University of Nebraska - Lincoln

DigitalCommons@University of Nebraska - Lincoln

Faculty Publications: Department of Entomology

Entomology, Department of

4-5-2007

\title{
Baseline susceptibility of western corn rootworm (Coleoptera: Chrysomelidae) to clothianidin
}

\author{
L.C. Magalhaes \\ University of Nebraska-Lincoln \\ B. W. French \\ USDA-ARS Northern Grain Insects Research Laboratory, Wade.French@ars.usda.gov \\ Thomas E. Hunt \\ University of Nebraska-Lincoln, thunt2@unl.edu \\ Blair D. Siegfried \\ University of Nebraska-Lincoln, bsiegfried1@ufl.edu
}

Follow this and additional works at: https://digitalcommons.unl.edu/entomologyfacpub

Part of the Entomology Commons

Magalhaes, L.C.; French, B. W.; Hunt, Thomas E.; and Siegfried, Blair D., "Baseline susceptibility of western corn rootworm (Coleoptera: Chrysomelidae) to clothianidin" (2007). Faculty Publications: Department of Entomology. 2.

https://digitalcommons.unl.edu/entomologyfacpub/2

This Article is brought to you for free and open access by the Entomology, Department of at DigitalCommons@University of Nebraska - Lincoln. It has been accepted for inclusion in Faculty Publications: Department of Entomology by an authorized administrator of DigitalCommons@University of Nebraska - Lincoln. 


\title{
Baseline susceptibility of western corn rootworm (Coleoptera: Chrysomelidae) to clothianidin
}

\author{
L. C. Magalhaes ${ }^{1}$, B. W. French ${ }^{2}$, T. E. Hunt ${ }^{3}$ and B. D. Siegfried ${ }^{1}$ \\ ${ }^{1}$ Department of Entomology, University of Nebraska, Lincoln, NE; ${ }^{2}$ USDA-ARS Northern Grain Insects \\ Research Laboratory, Brookings, SD; ${ }^{3}$ University of Nebraska, Haskell Agricultural Lab, Concord, NE, USA
}

Ms. received: November 27, 2006; accepted: January 03, 2007

\begin{abstract}
Western corn rootworm, Diabrotica virgifera virgifera LeConte, neonate susceptibility to clothianidin, a contact and systemic neonicotinoid insecticide, was determined from both laboratory and field-collected populations. Neonates were exposed to filter paper treated with increasing clothianidin concentrations and mortality was evaluated after $24 \mathrm{~h}$. Additionally, two populations were exposed to an artificial diet which was surface treated with clothianidin. Although larvae were five- to six-fold more sensitive to treated diet, results with treated filter paper were more reliable in terms of control mortality and required much less manipulation of rootworm larvae. Therefore, initial baseline comparisons were conducted using the filter paper assays. The variation among populations exposed to treated filter paper was generally low, 4.4-fold among laboratory populations tested; however, there was a 14.5-fold difference in susceptibility among all populations tested. In general, clothianidin was very toxic to rootworm neonates, with $\mathrm{LC}_{50}$ values ranging from 1.5 to $21.9 \mathrm{ng} / \mathrm{cm}^{2}$. These results indicate the practicability and sensitivity of the paper filter disc assay to establish baseline susceptibility levels, which is an essential first step in resistance management. A baseline response provides a reference for tracking shifts in susceptibility following commercialization of a control agent so that early changes in susceptibility can be detected.
\end{abstract}

Keywords: Diabrotica virgifera virgifera, bioassays, neonicotinoid, seed treatment

\section{Introduction}

Among the insect pests of US field corn (Zea mays L.) production, the western corn rootworm, Diabrotica virgifera virgifera LeConte (Col.: Chrysomelidae), is one of the most destructive. Control costs and crop losses combined are estimated to exceed $\$ 1$ billion annually in the United States (Metcalf 1986). Additionally, the western corn rootworm was recently detected in Europe in 1992 (Berger 2001). Because of the apparent existence of chronic trans-Atlantic introductions, it seems likely that western corn rootworm will become established in European corn-growing regions (Hemerik et al. 2004).

Management practices for western corn rootworm include soil insecticides for larval control and foliar insecticides and insecticidal baits that target ovipositing females. Rotation to a non-host crop, such as soybean, has also been an effective management practice, because rootworm larvae have an obligatory host relationship with corn and a few other graminaceous hosts (Levine and Oloumi-Sadeghi 1991). Crop rotation and chemical control have been the primary rootworm management strategies (Levine and OloumiSadeghi 1991), although D. v. virgifera has become increasingly difficult to control because of its sequential ability to evolve resistance to different classes of small molecule insecticides (Ball and Weekman 1963; Meinke et al. 1998; Zhou et al. 2002). Moreover, in areas where crop rotation has been the primary management strategy, rootworms have also evolved a 'behavioural' resistance involving oviposition in nonhost crops (O'Neal et al. 2001; Levine et al. 2002). Those eggs deposited outside cornfields can cause significant damage to corn planted in those fields in the following year. Soil insecticides, such as organophosphates and pyrethroids, are still effective but pose significant environmental and human health risks and are therefore unlikely to provide viable and long-term management options.

In 2003, the first commercial transgenic corn hybrids expressing the $\mathrm{Cry} 3 \mathrm{Bb} 1$ toxin derived from Bacillus thuringiensis $(\mathrm{Bt})$ were introduced for rootworm control. This toxin targets corn rootworms specifically and offers an alternative management option. However, this event does not express a high dose of toxin, and adult emergence from transgenic plants has been reported (Vaughn et al. 2005).

In addition to transgenic corn, seed treatments that employ neonicotinoid insecticides, such as clothianidin, may provide an additional management tool to control D. v. virgifera. Currently, in the United States, all Bt-protected corn seed is treated with a low rate of 
neonicotinoids (Mullin et al. 2005) to provide protection against a variety of secondary insect pests. Additionally, higher rates of seed treatments are recommended for rootworm control especially in refuge acres. The widespread use of clothianidin as a seed treatment could pose a high selective pressure and result in western corn rootworm populations that are resistant to this insecticide and potentially other neonicotinoids. Colorado potato beetle, Leptinotarsa decemlineata (Say), another important chrysomelid pest, has already evolved resistance to the neonicotinoid insecticide imidacloprid (Olson et al. 2000). Thus, efficient control practices such as clothianidin seed treatment and $\mathrm{Bt}$ toxins are dependent on effective monitoring programmes that are capable of early detection of resistance. As determined for Cry3Bb1 toxin (Siegfried et al. 2005), establishment of clothianidin baseline susceptibility levels among distinct geographical populations of $D$. $v$. virgifera is an essential first step in sustainable resistance management programmes.

The objective of the current study was to optimize methods for bioassay of western corn rootworm larval susceptibility to clothianidin and to establish a baseline of susceptibility from geographically distinct populations of this species.

\section{Materials and Methods}

\subsection{Insects}

Laboratory populations of western corn rootworms were initiated from field-collected adults during 1995-1996 and reared for five to seven generations at the USDA-ARS Northern Grain Insects Research Laboratory in Brookings, SD, using standard rearing techniques (Jackson 1986). A small number of populations were initiated from field-collected adults in 2005. The eggs from ovipositing females were collected in sifted soil (Jackson 1986), and each collection consisted of at least 400 ovipositing females. Collection sites for all populations are represented in fig. 1.

Eggs were shipped from the rearing facility to the University of Nebraska, Lincoln, NE, and incubated at $25^{\circ} \mathrm{C}$ and $60 \% \mathrm{RH}$ for 12 days. The eggs were then rinsed from the soil into a \#60 sieve, removing as much fine soil and debris as possible. Eggs were poured into a $50-\mathrm{ml}$ conical tube with excess water to isolate floating debris. The remaining eggs were then suspended in $1.25 \mathrm{M} \mathrm{MgSO}$, which causes the eggs to float. Soil and other debris sink to the bottom of the tube, so that they can be suctioned with a Pasteur pipette. $\mathrm{MgSO}_{4}$ flotation was repeated as necessary. The eggs were then disinfected to reduce microbial contamination by using techniques adapted from Pleau et al. (2002). Briefly, the eggs were cleaned first with Lysol disinfectant followed by $10 \%$ formalin for 2 min each and triple rinsed with sterile water. The eggs were pipetted onto Whatman no. 1 filter paper (Whatman, Maidstone, UK) in Petri dishes with vented lids (microbiological dishes, $47 \mathrm{~mm}$; Millipore Corporation, Billerica, MA) and incubated at $28^{\circ} \mathrm{C}$ until hatching.

\subsection{Feeding bioassays}

Bioassays were conducted by exposing neonates $(<24 \mathrm{~h}$ after hatching) to treated artificial diet dispensed into single wells of 96-well microtitre plates and surface treated with increasing concentrations of clothianidin. Technical clothianidin was provided by Bayer CropScience (Research Triangle Park, NC). The artificial diet used in all bioassays was prepared as described by Pleau et al. (2002). Five concentrations of clothianidin were used, and dilutions were made in $0.05 \%$ Triton X-100 non-ionic detergent to obtain uniform spreading onto the diet surface. Surface treatment of artificial diet has been shown to be an appropriate method for insecticide bioassays involving dietary exposure of neonate larvae (Siegfried et al. 2005). Each well was treated with $10 \mu \mathrm{l}$ of the appropriate solution and allowed to air dry for $1 \mathrm{~h}$ before transferring larvae to the treated diet. Control treatments consisted of diet treated with $0.05 \%$ Triton X-100 only. One neonate was transferred into each well using a camel-hair paintbrush. Wells were covered with Mylar plate sealers (Dynex Technologies, Chantilly, VA), and plates were held at $27^{\circ} \mathrm{C}$, 24-h scotophase and $80 \%$ RH. Mortality was recorded 4-7 days later.

\subsection{Filter paper assays}

Residual exposure bioassays were conducted by exposing neonates $(<24 \mathrm{~h}$ after hatching) to treated filter papers. Filter paper disks (Whatman no. $1001042,42.5 \mathrm{~mm}$ in diameter) were treated with $150 \mu \mathrm{l}$ of clothianidin dilutions

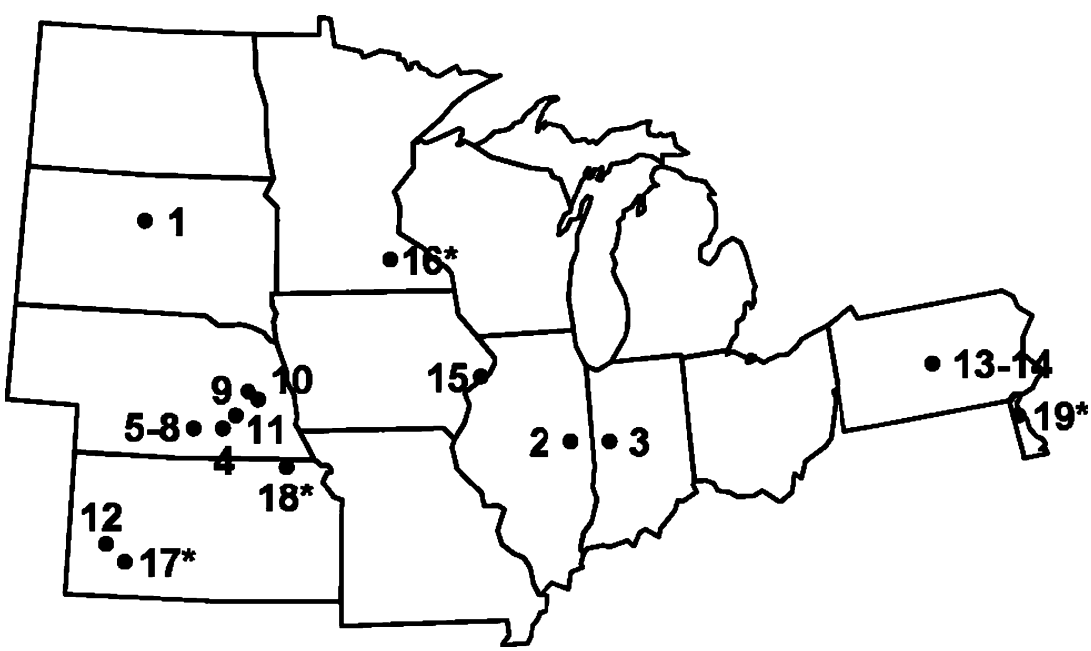

Fig. 1. Western corn rootworm collection sites across United States. Asterisk represents field colonies 
in double distilled water from a stock solution prepared in acetone. Larvae were exposed in Petri dishes $(47 \mathrm{~mm}$ in diameter, Millipore Corporation). Control treatments consisted of filter paper treated with double distilled water only. Acetone concentrations at the highest chlothianidin concentration were $<0.01 \%$ and did not significantly affect larval mortality. Filter papers were allowed to air dry for $5 \mathrm{~min}$, and 20 neonates were transferred into each Petri dish with a camel-hair paintbrush. Petri dishes were held at $27^{\circ} \mathrm{C}, 80 \%$ RH and 24-h scotophase. Mortality was recorded $24 \mathrm{~h}$ later and larvae were considered dead if they could not move the length of their body when prodded.

\subsection{Statistical analysis}

Only bioassays in which control mortality was $<20 \%$ were subjected to statistical analysis. Bioassays were conducted in duplicate on two different dates (total of four replicates), depending on availability of eggs. Each replicate included seven clothianidin concentrations with at least four concentrations that produced mortality between $0 \%$ and $100 \%$. Mortality data were analyzed by probit analysis (Finney 1971) using POLO-PC (LeOra Software 1987).

\section{Results and Discussion}

In general, for the two populations where data were obtained for both assay methods, larvae were five- to sixfold more sensitive to the treated diet than they were to the treated filter paper (fig. 2). Although clothianidin is generally more toxic through ingestion (W. Andersch, Bayer CropScience, personal communication), based on the rapid response to treated filter papers, it appears likely that rootworm larvae are sensitive to clothianidin through integumental exposure. Bioassays requiring exposure to artificial diet require longer exposure times (4-7 days) resulting in increased microbial contamination of the diet surface and high levels of control mortality (Siegfried et al. 2005). As a consequence, we initiated baseline susceptibility studies using exposure to filter paper treated with clothianidin.
Western corn rootworm laboratory and field populations surveyed were very susceptible to clothianidin (table 1). Lethal concentration (LC) 50 values for the laboratory populations ranged from $4.94 \mathrm{ng} / \mathrm{cm}^{2}$ (Clay Co., NE) to $21.93 \mathrm{ng} / \mathrm{cm}^{2}$ (York Co., NE), a 4.5-fold difference in susceptibility. Variability among fieldcollected adults was much less, ranging from $1.48 \mathrm{ng} /$ $\mathrm{cm}^{2}$ (Ford Co., KS) to $4.18 \mathrm{ng} / \mathrm{cm}^{2}$ (New Castle Co., DE). Surprisingly, field populations were generally more susceptible to clothianidin than laboratory populations suggesting possible adaptation to the laboratory conditions and increased fitness. In most cases, 95\% confidence limits overlapped, indicating there were no significant differences in susceptibility among these populations.

Although the residual exposure used to estimate baseline susceptibility may not adequately mimic exposure under field conditions where toxin ingestion through consumption of treated root tissue is likely, the residual exposure to treated filter paper offers several advantages over artificial diet assays. Feeding assays require careful handling of eggs and larvae to minimize microbial contamination of the diet surface, which causes high levels of control mortality. Exposure to filter paper treated with clothianidin solution reduces the exposure times, and control mortality is unaffected by microbial contamination that commonly occurs on diet surface. Consequently, mortality values were consistent, and control mortality did not exceed $20 \%$ in any of the populations examined. The filter paper assays also allowed larger sample sizes, reducing natural variability and are complete in $24 \mathrm{~h}$ relative to the $4-7$ days required for diet assays.

Although variation in susceptibility to clothianidin was observed, the magnitude of the difference among laboratory populations was relatively small (less than fivefold) (table 1). However, when all populations were compared, there was a 14.5 -fold difference in susceptibility. This result is similar to other estimates of baseline variability among geographically distinct
Fig. 2. Western corn rootworm susceptibility to chlothianidin through exposure to treated artificial diet or treated filter papers. Bars represents $95 \%$ confidence intervals

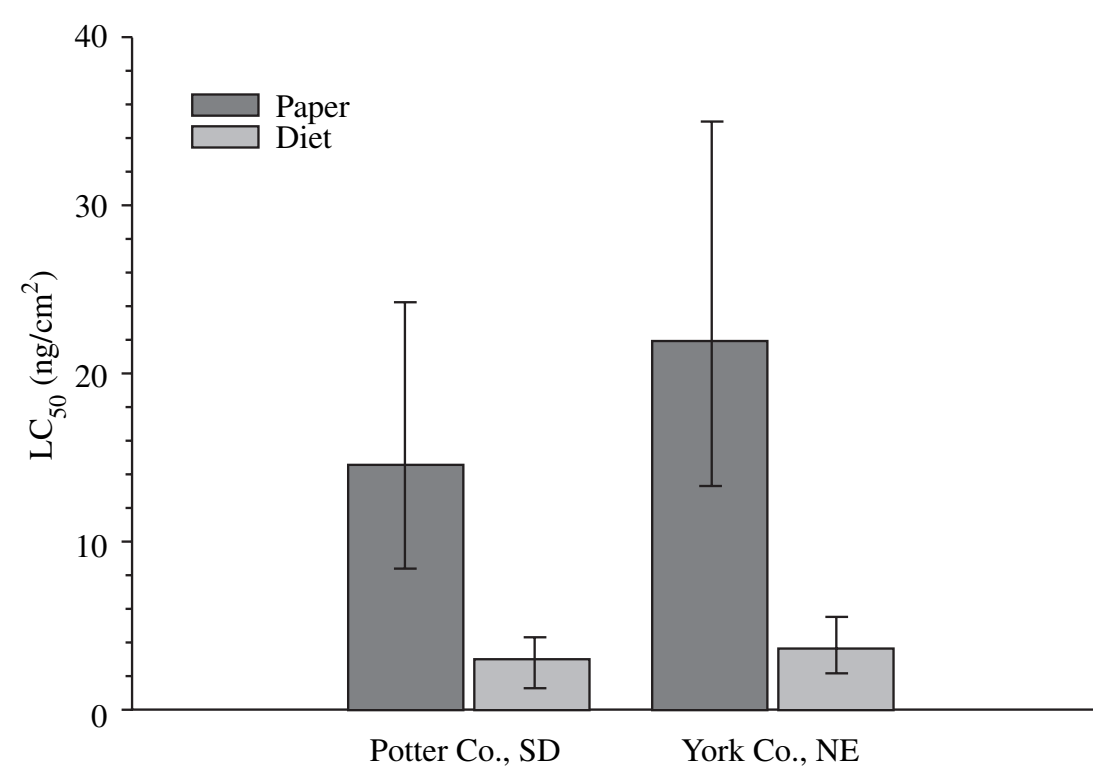


Table 1. Susceptibility of western corn rootworm neonates to clothianidin collected from field and laboratory populations maintained for five or six generations

\begin{tabular}{|c|c|c|c|c|c|}
\hline Laboratory colony & $\mathrm{LC}_{50}(95 \% \mathrm{CL}), \mathrm{ng} / \mathrm{cm}^{2}$ & $\mathrm{LC}_{90}(95 \% \mathrm{CL}), \mathrm{ng} / \mathrm{cm}^{2}$ & Slope \pm SE & $n$ & $\chi^{2}$ (d.f.) \\
\hline 1. Potter Co., SD & $14.52(7.83-24.31)$ & $130.53(65.16-520.20)$ & $1.34 \pm 0.15$ & 561 & $8.55(5)$ \\
\hline 2. Champaign Co., IL & $6.99(5.17-8.96)$ & $36.57(26.82-56.57)$ & $1.78 \pm 0.21$ & 630 & $0.87(5)$ \\
\hline 3. Tippecanoe Co., IN & $11.39(5.05-18.89)$ & $68.18(36.95-293.12)$ & $1.65 \pm 0.22$ & 606 & $9.88(5)$ \\
\hline 4. Clay $\mathrm{Co}, \mathrm{NE}$ & $4.94(3.50-6.45)$ & $30.50(22.29-47.57)$ & $1.62 \pm 0.19$ & 582 & $3.63(5)$ \\
\hline 5. Phelps Co., NE (1) & $7.81(4.89-11.36)$ & $46.76(28.65-110.3)$ & $1.65 \pm 0.20$ & 477 & $5.64(5)$ \\
\hline 6. Phelps Co., NE (2) & $9.93(6.69-13.91)$ & $53.72(34.99-104.85)$ & $1.75 \pm 0.19$ & 624 & $5.36(5)$ \\
\hline 7. Phelps Co., NE (3) & $6.87(3.61-11.33)$ & $41.57(22.47-144.70)$ & $1.64 \pm 0.18$ & 479 & $11.06(5)$ \\
\hline 8. Phelps Co., NE (4) & $8.67(4.85-13.39)$ & $44.20(25.93-128.30)$ & $1.81 \pm 0.20$ & 633 & $10.35(5)$ \\
\hline 9. Colfax Co., NE & $8.50(6.25-10.89)$ & $42.28(31.02-66.02)$ & $1.84 \pm 0.22$ & 640 & $4.93(5)$ \\
\hline 10. Saunders Co., NE & $18.67(11.23-30.11)$ & $72.61(41.20-296.40)$ & $2.17 \pm 0.29$ & 467 & $9.97(5)$ \\
\hline 11. York, Co., NE & $21.93(13.51-34.96)$ & $93.20(53.74-272.90)$ & $2.04 \pm 0.31$ & 329 & $5.31(5)$ \\
\hline 12. Finney Co., KS & $11.39(6.39-16.75)$ & $56.32(35.27-140.90)$ & $1.85 \pm 0.25$ & 649 & $6.46(5)$ \\
\hline 13. Centre Co., PA & $7.08(4.80-9.90)$ & $50.75(32.73-97.26)$ & $1.50 \pm 0.14$ & 652 & $5.14(5)$ \\
\hline 14. Centre Co., PA & $10.67(8.50-12.84)$ & $32.22(24.87-48.72)$ & $2.67 \pm 0.38$ & 479 & $1.65(5)$ \\
\hline 15. Scott Co, IA & $12.97(5.67-25.73)$ & $118.75(49.35-1162.20)$ & $1.33 \pm 0.18$ & 458 & $10.99(5)$ \\
\hline 16. Rice Co., MN* & $2.00(0.48-3.67)$ & $7.27(3.96-36.47)$ & $2.29 \pm 0.39$ & 299 & $10.78(5)$ \\
\hline 17. Ford Co., KS* & $1.48(0.57-2.69)$ & $15.28(8.58-37.09)$ & $1.27 \pm 0.14$ & 647 & $8.26(5)$ \\
\hline 18. Nemaha Co., KS* & $3.03(1.22-4.80)$ & $12.26(7.86-27.74)$ & $2.11 \pm 0.34$ & 479 & $6.72(5)$ \\
\hline 19. New Castle Co., DE* & $4.18(0.92-6.36)$ & $11.24(7.62-29.02)$ & $2.99 \pm 0.73$ & 361 & $5.81(5)$ \\
\hline
\end{tabular}

populations of western corn rootworm for both synthetic neurotoxic insecticides (Zhu et al. 2005) and Cry toxins from B. thuringiensis (Siegfried et al. 2005). Robertson et al. (1995) reported a 12.5-fold difference among cohorts of the same population of colorado potato beetle. So far, there are no reports of clothianidin control failures, and field populations of western corn rootworms (table 1) had lower $\mathrm{LC}_{50}$ values compared with colony populations. Thus, the variation observed in this study is probably related to natural variation because the laboratory populations were never exposed to clothianidin.

Some of the populations included in these experiments have previously been shown to exhibit high levels of resistance to methyl parathion (Parimi et al. 2006). In particular, collections from Phelps and York Counties in Nebraska (Meinke et al. 1998; Parimi et al. 2006) have previously been shown to exhibit in excess of 20-fold resistance to methyl parathion. Importantly, there was no indication of elevated tolerance to clothianidin among these populations (table 1) and therefore cross-resistance does not appear to pose a threat to clothianidin efficacy in areas where organophosphate resistance has been documented.

Generating baseline susceptibility data represents the first step towards the development of a monitoring programme designed to detect changes in susceptibility that may result from repeated and prolonged pesticide exposure under field conditions. When combined with new Bt corn hybrids, neonicotinoid-treated seeds should provide an important $D$. v. virgifera control option, even in continuous corn production areas. Seed treatments may provide an important management option in Europe where control options may be limited. Given the rapid and widespread adoption of this technology, vigilant monitoring for changes in susceptibility will be essential to its long-term sustainability.

\section{Acknowledgements}

The authors thank Dr. Michael Schwarz (Bayer CropScience, Research Triangle Park, NC) for providing clothianidin technical grade and financial support for this research. We also thank Terence Spencer for his assistance in conducting the assays.

\section{References}

Ball HJ, Weekman GT, 1963. Differential resistance of corn rootworms to insecticides in Nebraska and adjoining states. J. Econ. Entomol. 56, 553-555.

Berger HK, 2001. The western corn rootworm (Diabrotica virgifera virgifera): a new maize pest threatening Europe. Bull. OEPP 31, 411-414.

Finney DJ, 1971. Probit analysis. Cambridge University Press, Cambridge.

Hemerik L, Busstra C, Mols P, 2004. Predicting the temperature-dependent natural population expansion of the western corn rootworm, Diabrotica virgifera. Entomol. Exp. Appl. 111, 59-69.

Jackson JJ, 1986. Rearing and handling of Diabrotica virgifera and Diabrotica undecipunctuata howardi. In: Methods for the study of pest Diabrotica. Ed. by Krysan JL, Miller TA, Springer, New York, 25-47.

LeOra Software, 1987. POLO-PC. A user's guide to probit and logit analysis. Berkeley, CA.

Levine E, Oloumi-Sadeghi H, 1991. Management of diabroticite rootworms in corn. Annu. Rev. Entomol. 36, 229-255.

Levine E, Spencer J, Isard SA, Onstad DW, Gray ME, 2002. Adaptation of the western corn rootworm, Diabrotica virgifera virgifera LeConte (Coleoptera: Chrysomelidae) to crop rotation: evolution of a new strain in response to a cultural management practice. Am. Entomol. 48, 94-107.

Meinke LJ, Siegfried BD, Wright RJ, Chandler LD, 1998. Adult susceptibility of Nebraska western corn rootworm (Coleoptera: Chrysomelidae) populations to selected insecticides. J. Econ. Entomol. 91, 594-600. 
Metcalf RL, 1986. Methods for the study of pest Diabrotica. Springer, New York.

Mullin CA, Saunders MC, Leslie TW, Biddinger DJ, Fleischer SJ, 2005. Toxic and behavioral effects to Carabidae of seed treatments used on Cry3Bbl- and Cry $1 \mathrm{Ab} / \mathrm{c}$-protected corn. Environ. Entomol. 34, 1626-1636.

O’Neal ME, Gray ME, Ratcliffe S, Steffey KL, 2001. Predicting western corn rootworm (Coleoptera: Chrysomelidae) larval injury to rotated corn with pherocon AM traps in soyabeans. J. Econ. Entomol. 94, 98-105.

Olson ER, Dively GP, Nelson JO, 2000. Baseline susceptibility to imidacloprid and cross resistance patterns in Colorado potato beetle (Coleoptera: Chrysomelidae) populations. J. Econ. Entomol. 93, 447-458.

Parimi S, Meinke LJ, French BW, Chandler LD, Siegfried BD, 2006. Stability and persistence of aldrin and methylparathion resistance in western corn rootworm populations (Coleoptera: Chrysomelidae). Crop Prot. 25, 269-274.

Pleau MJ, Huesing JE, Head GP, Feir DJ, 2002. Development of an artificial diet for the western corn rootworm. Entomol. Exp. Appl. 105, 1-11.

Robertson JL, Preisler HK, Ng SS, Hickle LA, Gelernter WD, 1995. Natural variation - a complicating factor in bioassays with chemical and microbial pesticides. J. Econ. Entomol. 88, 1-10.
Siegfried BD, Vaughn TT, Spencer T, 2005. Baseline susceptibility of western corn rootworm (Coleoptera: Crysomelidae) to Cry3Bb1 Bacillus thuringiensis toxin. J. Econ. Entomol. 98, 1320-1324.

Vaughn T, Cavato T, Brar G, Coombe T, DeGooyer T, Ford S, Groth M, Howe A, Johnson S, Kolacz K, Pilcher C, Purcell J, Romano C, English L, Pershing J, 2005. A method of controlling corn rootworm feeding using a Bacillus thuringiensis protein expressed in transgenic maize. Crop Sci. 45, 931-938.

Zhou XG, Scharf ME, Parimi S, Meinke LJ, Wright RJ, Chandler LD, Siegfried BD, 2002. Diagnostic assays based on esterase-mediated resistance mechanisms in western corn rootworms (Coleoptera: Chrysomelidae). J. Econ. Entomol. 95, 1261-1266.

Zhu KY, Wilde GE, Sloderbeck PE, Buschman LL, Higgins RA, Whitworth RJ, Bowling RA, Starkey SR, He F, 2005. Comparative susceptibility of western corn rootworm (Coleoptera: Chrysomelidae) adults to selected insecticides in Kansas. J. Econ. Entomol. 98, 2181-2187.

Author's address: Blair D. Siegfried (corresponding author), Department of Entomology, University of Nebraska, 202 Plant Industry Building, Lincoln, NE 68583-0816, USA. Email: bsiegfried1@unl.edu 